$16^{\text {th }}$ International Congress of Metrology, 02005 (2013)

DOI: $10.1051 /$ metrology/201302005

(C) Owned by the authors, published by EDP Sciences, 2013

\title{
Measurement of flow rate at terminal device
}

\author{
Isabelle Caré \\ CETIAT, Domaine scientifique de la Doua, 25 avenue des Arts, 69100 Villeurbanne Cedex, France
}

\begin{abstract}
Measurement of air flow is an important part of the commissioning and monitoring of ventilation installations both for residential and tertiary sectors. In the case of the measurement of flow rate at air terminal devices, an experimental approach highlights the practical limitations related to the usual methods available for on site measurements and the influence of the used instruments. The purpose of the present work is to make a critical analysis of the on site air flow measurement methods with regard to measurement configurations.
\end{abstract}

\section{Introduction}

The perception of the interior climate of a building by those who work or live there is strongly dependent of the construction, function and maintenance of ventilation installations. The control of the ventilation air flow is essential to ensure a good air quality. Indeed, a too low airflow can have serious sanitary consequences. A too high airflow, in addition with discomfort, leads to an energy overconsumption which is not compatible with the changes in regulations.

During the commissioning or maintenance phases of ventilation installations, the measurement of air flow becomes a parameter which has to be considered carefully. The judgement of conformity has to be based on measurement methods which are reliable and then which have not only low enough and but also known measurement uncertainties. Different measurement methods are developed and sometimes standardised [1,2, $3]$ to enable the commissioning and operational monitoring of ventilation installations at terminal devices. These methods are strongly different depending on whether it is desired to measure a low flow rate at a small size terminal device or a higher one at a diffuser (which can be very various in size and in shape). According to the size and shape of some examples of terminal devices, the paper describes different air flow measurement methods which can be easily used on site. The measurement of air flow is obtained by instruments measuring air speed, pressure or directly airflow. A comparison of the different methods is performed in term of measurement accuracy.

\section{Experimental setup}

To evaluate the measurement quality of the different on site methods, exhaust and supply air terminal devices are connected to a test rig which lets to generate, control and measure a reference air flow. This test rig consists of a plenum chamber, a fan with a variable rotation speed to generate the flow and some elements allowing a reference flow rate. According to the flow rate, the reference value is measured by a nozzles (figure 1a) or flow meter (figure 1b).

Figure 1. Photos of the test rigs used for the determination of a reference flow rate
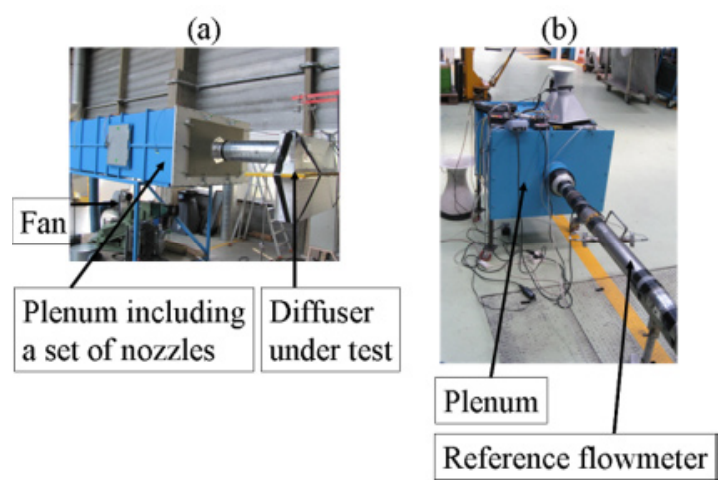

The flow rate at the terminal device measured by the different on site methods is compared to the reference flow rate.

\section{Results}

Two different types of air terminal devices are considered in this study.

\subsection{Supply and Exhaust air terminal devices}

The first one is characterized by its small size (about $200 \mathrm{~mm}$ by $200 \mathrm{~mm}$ ). It can be found in residential houses but also in service buildings. These air terminal devices can be used to supply or exhaust air.

\footnotetext{
a Corresponding author: isabelle.care@cetiat.fr
} 
The flow rate is less than $200 \mathrm{~m}^{3} / \mathrm{h}$ and the flow direction may be strongly disturbed near the device according to its geometry. Some examples of the tested devices are shown on the figure 2 below.

Figure 2. Tested air terminal devices

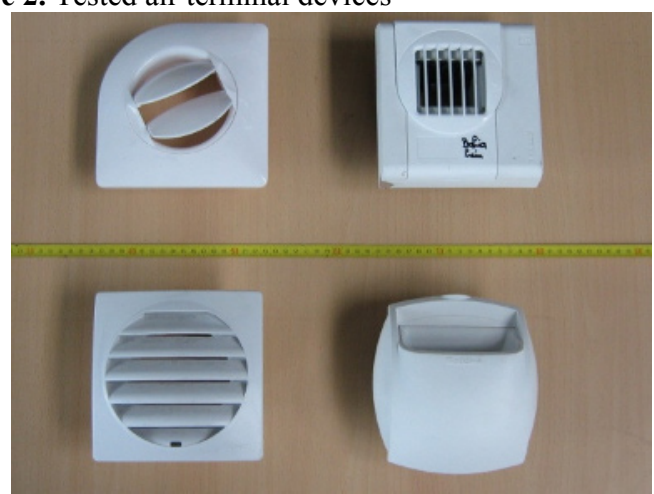

To measure the flow rate on site, the simplest way is to use an anemometer placed in the smallest section of a cone or a funnel. The anemometer can be a thermal (figure $3 a$ ) a vane (figure $3 b$ ) one and it fits to the cone. Some anemometers' manufacturers propose these cones as accessories.

Figure 3. Photos of the anemometers and their funnel used for the flow measurement. (a) thermal anemometer, (b) vane anemometer (Doc. KIMO) (a)

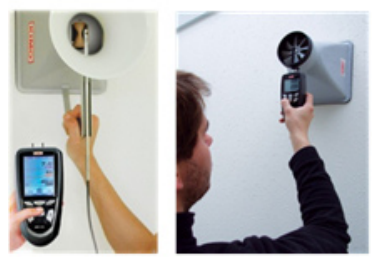

In some conditions, it can also be possible to measure the flow rate indirectly by the mean of a pressure measurement.

In the case of a terminal device with a low flow deviation and a low flow rate, the figure 4 below shows the expected error when using a vane anemometer or a thermal one with a funnel to measure directly the flow rate.

Figure 4. Example1 of the error evaluation of the direct flow measurement methods using an anemometer with a funnel

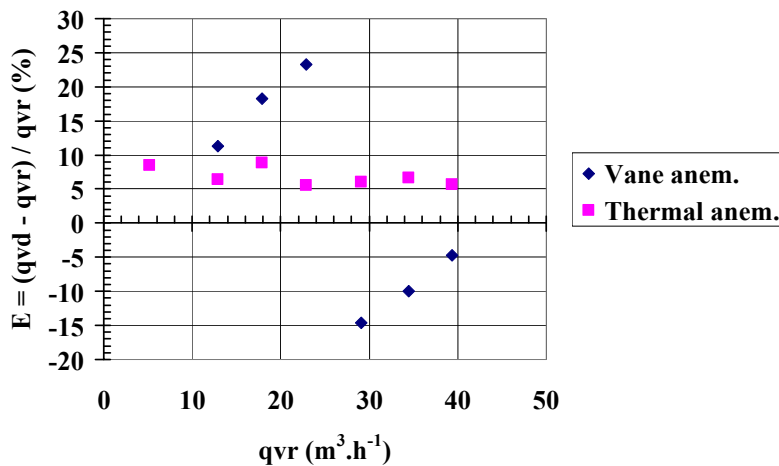

Within this flow range, the method using a vane anemometer is not satisfactory. Because of its working principle, the anemometer presents a start threshold and this kind of anemometer is clearly not adapted to measure low velocities and has a consequence low flow rate.

When the flow rate is slightly higher but the flow strongly deviated at the exit (or inlet) of the terminal device, the behaviour of the two measurement systems is quite different, as shown on the figure 5 below.

Figure 5. Example2 of the error evaluation of the direct flow measurement methods using an anemometer with a funnel (TA: Thermal anemometer, Vane: vane anemometer)

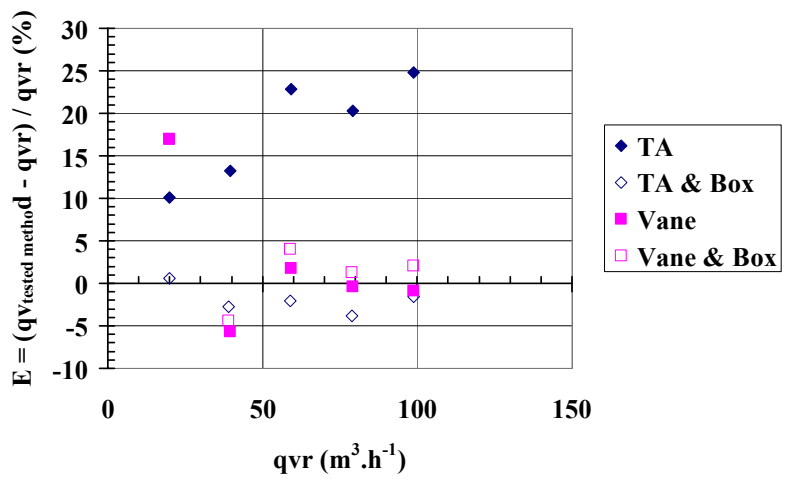

The so-called "Box" in the former figure is an extension that allows the anemometer and its cone away from the wall where the air terminal device is.

In the example presented above where the flow deviated, the results obtained with the thermal anemometer are quite bad. The reason is the small size of the measurement volume of the thermal anemometer. On the contrary the measurement section of the vane anemometer is over the whole section of the cone and the results are quite satisfactory at these higher flow rates. In the case of the thermal anemometer, the measurement can be improved by moving the instrument away from the air terminal device simply with an extension, the so-called "Box".

\subsection{Supply and Exhaust diffusers}

For the second type of air terminal devices on which the tests have been performed, the size and the shape can be very different as shown on the figure 6 below.

Figure 6. Tested air terminal diffusers (a)

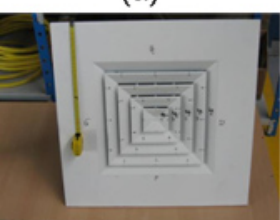

(b)

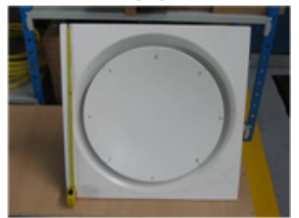

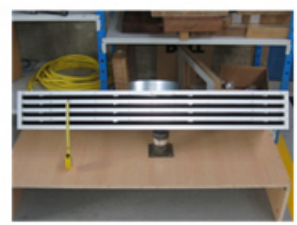

(c)

These air terminal diffusers can be used to supply or exhaust air. 
The flow rate is usually between 100 and $1000 \mathrm{~m}^{3} / \mathrm{h}$ and the flow direction may be strongly disturbed near the diffuser according to its geometry.

The flow rate can be measured directly with a flow hood if the dimensions of the hood are adjusted to those of the diffuser (figure $7 a, 7 b$ ). If not, the flow rate is determined indirectly by measuring air velocities at the exit of the diffuser (figure $7 \mathrm{c}$ ) or pressure in the plenum under certain conditions.

Figure 7. Examples of flow hoods (a, b) (Doc TSI) and air velocity measurements at the exit of the diffuser (c) (a)

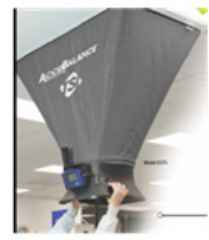

(b)

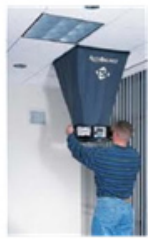

(c)

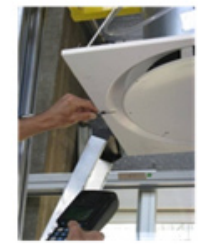

The figure 8 and 9 below show the results obtained for the diffusers $6 a$ and $6 \mathrm{~b}$ resp. when the measurement method is based on velocity measurements at the exit of the diffuser, on pressure measurements in the plenum of the diffuser or directly with a flow hood. Two different flow hoods have been tested.

Figure 8. Measurement results of the flow rate with the diffuser $6 \mathrm{a}$

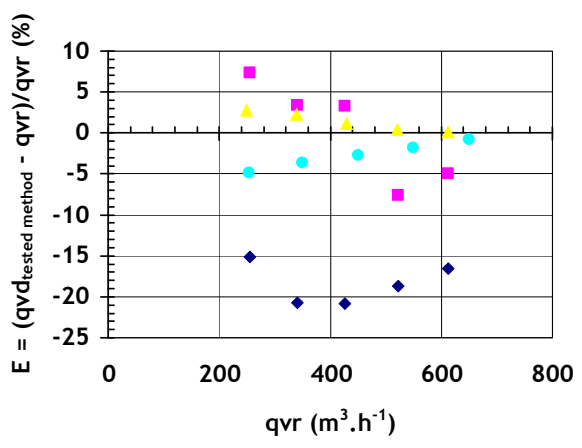

- Velocity meas. - Pressure meas. Flow hood 1 - Flow hood 2

Figure 9. Measurement results of the flow rate with the diffuser $6 \mathrm{~b}$

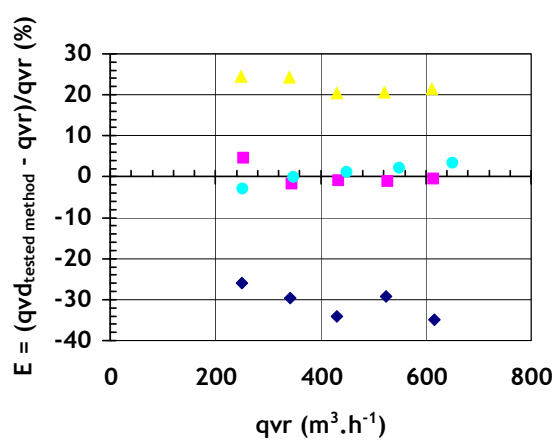

- Velocity meas.

- Pressure meas. Flow hood 1

- Flow hood 2 the manufacturer. The flow rate is calculated from the following equation:

$$
q v=A_{k} \times V_{k}
$$

where $q v$ is the calculated volume flow rate, $A_{k}$ is the diffuser section (given by the manufacturer) and $V_{k}$ is the mean velocity at the exit of the diffuser. This mean velocity is the mean of the velocities measured at the exit of the diffuser.

The result is strongly dependent on the velocity distribution at the exit of the diffuser, the number of measurement points. This velocity area method which is also time consuming should be preferably not chosen.

On the contrary the pressure measurement method gives quite good results. However, a pressure coefficient is necessary and should be given by the manufacturer. If not, the method is not available.

Concerning the flow hood method, it can be seen that according the flow structure, the results are quite different. In the case of a symmetrical flow at the exit of the diffuser (cf figure 8), the method is quite satisfactory with the two flow hoods. In the case of a flow with a swirl as in the case of diffuser presented on figure $6 \mathrm{~b}$ (cf figure 9) the results obtained with the flow hood1 are not as good as those obtained with the flow hood 2.

Nevertheless, for on site measurements, the use of a flow hood seems to be the better solution insofar as a hood with the dimension of the diffuser is available.

Concerning the flow measurement for diffusers such as the one presented on figure $6 \mathrm{c}$, it is often not possible to find a hood with the appropriate dimensions. The pressure measurements are not appropriate too because the relative pressure in the plenum is too low. The velocity measurement method is then the only possible. Nevertheless, the lack of knowledge of the effective section $A k$ is the same are more conventional diffusers. A solution is to use an extension to perform measurement in a know section. The experimental set-up is presented on the figure 10 below.

Figure 10. Linear diffuser with and without extension on the test reig

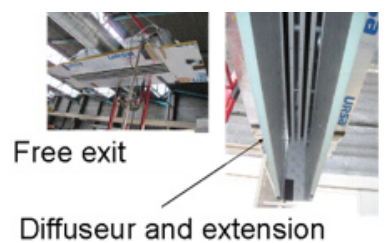

The benefit on the extension is clearly seen on the figure 11 below. This extension has two advantages: first, the section, $A k$, is well known. Second, the measurements are performed in a section where the velocity profile is less disturbed that at the exit of the diffuser.

As it can be seen on the two figures above, the results obtained with the velocity measurements method are quite bad. In fact, the result depends strongly on the position of the velocity measurement at the exit of the diffuser as well as its section, which might be given by 
Figure 10. Measurement results of the flow rate for a linear diffuser. Comparison of the different methods

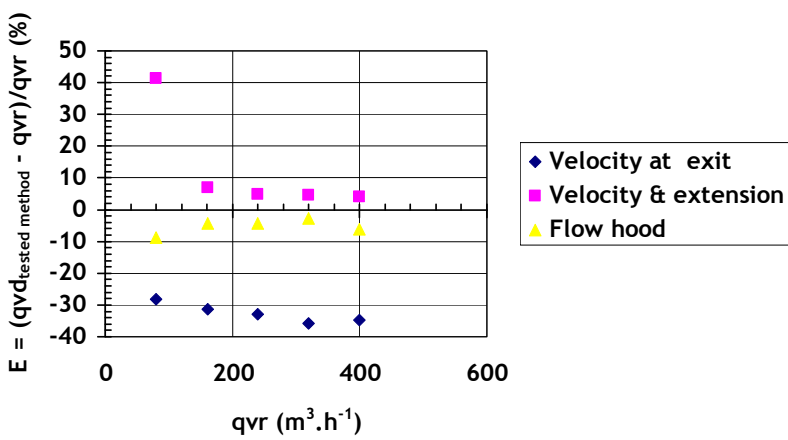

The flow hood gives also good results in this case where the hood is adapted to the rectangular shape of the diffuser.

\section{Conclusions}

The performed measurements show that according to the measurement conditions, some methods are appropriate and others not at all for on site measurement. Before choosing a method, the experimental conditions have then to be deeply investigated.

All the presented results and others are gathered in a Good Practice Guide for on site air flow measurement. This Guide in French is available on CETIAT Web site as a free download.

\section{Acknowledgments}

ALDES and CIAT companies are thanked for their active contribution to the work presented here. The DGCIS service of the Ministry for Industrial Renewal is thanked for its financial support.

\section{References}

1. NF EN 12599, Ventilation des bâtiments. Procédures d'essai et méthodes de mesure pour la réception des installations de ventilation et de climatisation installées, (2000)

2 NF EN 14134, Ventilation des bâtiments. Essai de performances et contrôles d'installation des systèmes de ventilation résidentiels, (2004)

3 Pr NF EN 16211, Ventilation for buildings Measurement of air flows on site -methods, (to be published) 